with those of Ley \& Locascio (1969), who found that within levels of M, RT of stimulus terms, in forward anticipation learning, had no effect on PAL, but in a backward recall test, RT of response terms (stimulus terms in the forward anticipation learning task) had a significant effect (i.e., short-latency RT terms were recalled more frequently than long-latency terms). Again, $M$ was a significant variable in both learning tasks.

The Familiarization by $M$ interaction provides additional evidence that within levels of $\mathrm{M}$, the role of $\mathrm{RT}$ in PAL is different from that of $M$. Consistent with the predictions of the present study, learning the low-M response pairs was facilitated by familiarization trials (findings consistent with those of Schulz \& Martin, 1964), whereas familiarization did not interact significantly with RT.

The results of the present study are consistent with the hypothesis put forth by Ley \& Locascio (1969), viz, recognition or pronunciability or Martin's (1968) perceptual encoding are all indexed by $M$ and are processes separate from recall. Further, since, within levels of $\mathrm{M}$, the effect of RT is limited to the term of the PA that is required to be recalled, it is conceivable that RT, although highly correlated with $M$, is the variable underlying recall, i.e., short-latency RT units may be recalled more readily than long-latency RT units.

REFERENCES

BATTIG, W, F., \& SPERA, A. I. Rated association values of numbers from 0-100. Journal of Verbal Learning \& Verbail Behavior, 1962, 1, 200202.

GOSS, A. E. Comments on Professor Noble's paper. In C. N. Cofer and B.S. Musgrave (Eds.), Verbal behavior and learning problems and processes. New York: McGraw-Hill, 1963. Pp. 119-155.

GOSS, A. E., \& NODINE, C. F. Paired-associates learning: The role of meaningfulness. similarity, and familiarization. New York: Academic Press, 1965.

LEY, R. Associative reaction time, meaningfulness, and presentation rate in paired-associate learning. Journal of Experimental Psychology, 1968, 78, 285-291.

LEY, R., \& ANDERSON, L. Associative reaction time of response terms in paired-associate learning. Journal of Experimental Psychology, $1969,79,378-380$.

LEY, R, \& LOCASCIO, D. Associative reaction time and meaningfulness of stimulus terms in paired-associate learning and stimulus recall. Paper presented at the Psychonomic Society meeting, St. Louis, Missouri, November 1969.

LEY, R., \& LOCASCIO, D. Associative reaction time and meaningfulness of CVCVC response terms in paired-associate learning. Journal of Experimental Psychology, 1970, 83, 445-450.

MARTIN, E. Stimulus meaningfulness and paired-associate transfer: An encoding variability hypothesis. Psychological Revjew, $1968,75,421.441$

SCHULZ, R. W., \& MARTIN, E. Aural paired-associate learning: Stimulus familiarization, response familiarization, and pronounciability. Journal of Verbal Learning \& Verbal Behavior, 1964, 3, 139-145.

TAYLOR, J. Meaningfulness of 320 words and paralogs. Unpublished doctoral dissertation, Duke University, 1959.

UNDERWOOD, B. J., \& SCHULZ, R. W. Meaningfulness and verbal learning. Chicago: Lippencott, 1960.

\title{
Recognition memory for words presented at a slow or rapid rate*
}

\author{
ARTHUR I. SCHULMAN and EUGENE A. LOVELACE \\ University of Virginia, Charlottesville, Va. 22901
}

Fast presentation (about 1 word/sec) impairs subsequent recognition of both common and very rare words. This presentation rate, slow enough for accurate perception but probably too fast for much more elaborate information processing, also sharply reduces the variability of recognition memory scores.

In studies of the ability to recognize words recently seen, investigators have overlooked the importance of the rate at which the words are originally presented.

\footnotetext{
*The research described in this paper was first reported at the 1967 meeting of the Psychonomic Society.
}

They have chosen their rates more or less arbitrarily, so that a word's exposure duration almost always has fallen within the range of $2-5 \mathrm{sec}$. Over this range, later recognition performance seems to vary only slightly and unsystematically (Egan, 1958; Schulman, 1967; Shepard, 1967). It is as if normal processing of the words presented could be completed within $2 \mathrm{sec}$ or 30 , additional exposure time being superfluous. If sufficiently less than $2 \mathrm{sec}$ we re allotted each word, however, performance in recognition memory would surely decline. Brief (but not tachistoscopic) exposures, long enough for accurate perception but too short for much more elaborate information processing, should impair recognition memory to the extent that this memory for recent experience depends upon such processing. Moreover, sufficiently brief exposures may be expected to curtail opportunities for idiosyncratic encoding and, consequently, to reduce variability among Ss. The present experiment shows that recognition memory indeed suffers and that variability is reduced when a suitably fast presentation rate is used.

\section{METHOD}

Two presentation sequences were prepared. One consisted entirely of common English words, the other entirely of very rare English words. A group of Ss was confronted with one of these sequences, at either a slow or a fast rate, and then was tested for recognition. Two Kodak Carousel slide projectors were connected in tandem and externally timed to produce the fast rate, which exposed each word for $1.00 \mathrm{sec}$, or the slow rate, which exposed each word for $4.25 \mathrm{sec}$. There was about $0.75 \mathrm{sec}$ of change-time between slides. Two hundred common words were drawn selectively from the 1,000 most frequently occurring English words, as listed by Thorndike \& Lorge (1944); 200 rare words, a majority of which had probably never before been seen by any of our Ss, were drawn selectively from Cieutat (1963). Within each group of 200 words, structural similarity was avoided, and only words of two or more syllables were allowed. ${ }^{1}$ of the 200 words in each group, 100 at random were selected for the presentation sequence. These "old" words were then interspersed among the 100 remaining "new" words on the test of recognition memory that followed. The Ss knew that the presentation sequence was to be followed by a recognition test. Only a few minutes for instructions separated the two phases of the experiment. The recognition test was in booklet form, and S worked at his own pace. Alongside each of the 200 test words, $\mathrm{S}$ recorded his confidence, using a 6-point scale, that the word was "old." The $2 \times 6$ data matrix so determined-i.e., the six responses distributed over the event categories "old" and "new"-may be represented as pairs of increasing, accumulated proportions and plotted as points to which an operating characteristic (OC) may be fitted [see 


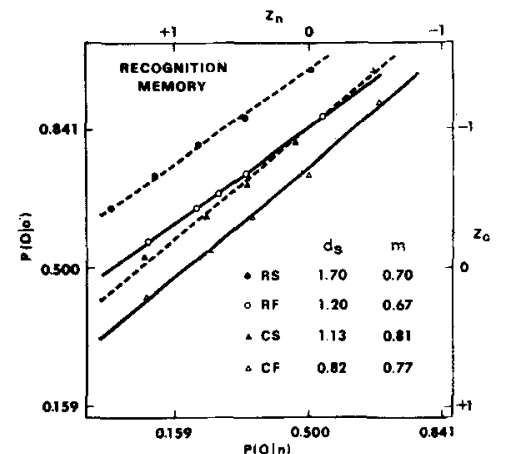

Fig. 1. Operating characteristics on normal-normal coordinate paper. Each $O C$ was fitted by eye to the data points. $R$ and $C$ denote the rare and common word lists, while $S$ and $F$ denote the slow and fast rates of presentation.

Green \& Swets (1966) for procedural details and a rationale for the use of the rating method to determine OCs]. Such OCs therefore represent the proportion of old words judged to be old, i.e., $\mathrm{P}(\mathrm{O} \mid \mathrm{o})$, as a function of the proportion of new words judged to be old, i.e., $P(O \mid n)$, and reflect the difficulty in discriminating new words from old. When plotted on normal-normal coordinate paper, these OCs for recognition memory usually can be described as linear functions. As such, they can be summarized by two parameters: $m$, the slope of the $O C$, and $d_{s}$, a measure of sensitivity whose value is the difference between the z-score coordinates of the point on the $O C$ that lies on the negative diagonal.

Undergraduates enrolled in introductory classes in psychology served as Ss to meet a course requirement. For the rare-fast (RF) group, $N=22$; for the rare-slow (RS) group, $\mathrm{N}=17$; for the common-fast (CF) group, $\mathrm{N}=21$; and for the common-slow (CS) group, $\mathrm{N}=20$. All $\mathrm{Ss}$ in a given group were tested at the same time.

\section{RESULTS AND DISCUSSION}

Responses from all Ss within a group were pooled so that an $O C$ for the group might be determined. These four $\mathrm{OCs}$, each based on $200 \cdot \mathrm{N}$ responses, are shown in Fig. 1. It is clear that the tast rate of presentation substantially impaired recognition memory for both common and rare words, and to the same extent; $d_{s}$, the index of discriminability of old and new words, was for both lists about 30\% less after fast presentation than after slow. Smaller differences between fast and slow presentation rates have recently been reported by Kintsch (1967) for a continuous recognition task using four-digit numbers as stimuli.

Note that recognition was much better for rare words than for common words under both presentation rates. In a recent experiment, Schulman (1967) found comparable differences in recognizability, despite the fact that his "rare" words were much commoner than ours, occurring once per million, according to the Thorndike-Lorge (1944) G count. It is clear, then, that rare words, although harder to recall, are easier to recognize than common words. What is also apparent is that their greater distinctiveness cannot depend entirely on their more specialized meanings (but see Allen \& Garton, 1968), since so many rare words in the present study were totally unfamiliar ones, e.g., "pagrus" and "zabeta." Now, it can be shown that rare words differ significantly in structure from common words, for instance, in their greater incidence of unusual digrams. The structural information carried by low-frequency digrams, trigrams, and syllables make rare words potentially more distinctive than common ones. Whether or not people actually use such structural information is an open question but one that may be more important for recognition memory than most of us have suspected.

The fast rate of presentation not only resulted in lower average performance in recognition memory, but in reduced individual differences as well. We can better evaluate this homogenizing effect of the fast rate if we characterize each S's performance, not by $d_{s}$, but instead by the proportion of correct decisions, $\mathrm{P}(\mathrm{C})$, associated with his operating point nearest the negative diagonal. If we treat $P(C)$ as if it were the probability of success, $p$, in a binomial experiment of 200 trials, we then can compare measured variance with binomial variance, $p(1-p) / 200$. For each experimental group the mean and standard deviation of $P(C)$ follow, with the calculated binomial $\sigma$ in parentheses: CS, .710 and $.100(.032)$ vs $\mathrm{CF}, .651$ and .058 (.034); and RS, .804 and .084 (.028) vs RF, .731 and .061 (.031). The lower variability associated with the fast rate is statistically significant for the common list of words, $F(19,20)=2.97, p<.05$, but not for the rare list, $F(21,16)=1.91$, $p>.05$. However, a single extreme outlier with $\mathrm{P}(\mathrm{C})=.575$ is responsible for much of the variance of the RF group. When we remove this $\mathrm{S}$, his group's standard deviation drops to .040, and the variance-ratio for the two rare-word groups becomes highly significant, $F(21,15)=4.29, p<.01$. Moreover, 34 of the $38 \mathrm{Ss}$ in the fast groups scored within 2 binomial $\sigma$ of the average $\mathrm{P}(\mathrm{C})$ for their group. For the two slow groups, in contrast, only 20 of the 43 Ss scored within 2 binomial $\sigma$ of their group's average $P(C)$. The fast rate used in the present experiment thus produced variability that begins to approach binomial variability, despite the fact that average recognition performance remained well above chance. It seems reasonable to suppose that the slow rate allowed individual differences in encoding, association, etc., to come into play, whereas the fast rate served to curtail idiosyncratic information processing.

In conclusion, it is clear that a sufficiently fast presentation rate can reduce both the average $\dot{a}_{s}$ and the variability of recognition memory scores. The decrement in $d_{s}$ may derive from insufficient time for all habitual modes of elaboration of a perceived word to be employed. Words are encoded, that is to say, with reduced cues for their later retrieval or recognition. The time needed to complete all normal processing would seem to be between 1 and $2 \mathrm{sec}$, since previous studies show that Ss do not seem to gain from exposures prolonged beyond $2 \mathrm{sec}^{2}$ The homogenizing effect of a rapid presentation rate suggests that, beyond perception, the first elaborations of a verbal input are remarkably alike for adults. Later elaborations, presumably more idiosyncratic, are curtailed under the pressure of time.

\section{REFERENCES}

ALLEN, L. R., \& GARTON, R.F. The influence of word-knowledge on the word-frequency effect in recognition memory. Psychonomic Science, 1968, 10, 401-402.

CIEUTAT, V. Association indices for 446 randomly selected English monosyllables, bisyllables, and trisyllables. Journal of Verbal Learning \& Verbal Behavior, 1963, 2, 176-185.

EGAN, J. P. Recognition memory and the operating characteristic. Indiana University: Hearing and Communication Laboratory, Technical Note AFCRC-TN-58-51, 1958.

GREEN, D. M., \& SWETS, J. A. Signal detection theory and psychophysics. New York: Wiley. 1966. Pp. 337-345.

KINTSCH, W. Memory and decision aspects of recognition learning. Psychological Review, $1967,74,496-504$.

SCHULMAN, A. I. Word length and rarity in recognition memory. Psychonomic Science, 1967, 9, 211-212.

SHEPARD, R. N. Recognition memory for words, sentences, and pictures. Journal of Verbal Learning \& Verbal Behavior, 1967, 6, 156-163.

THORNDIKE, E. L., \& LORGE, I. The teacher's word book of 30,000 words. New York: Bureau of Publications, Teachers College, Columbia University, 1944.

$$
\text { NOTES }
$$

1. The complete lists are available from the authors upon request.

2. Whereas presentation times greater than $2 \mathrm{sec}$ seem not to benefit recognition memory, repeated presentations do. When Egan (1958) presented two random orders of the same word list, allowing $3 \mathrm{sec}$ per word each time, $\mathrm{d}_{\mathrm{S}}$ was about twice that for a single presentation of the list. 